\title{
The Influence of Group Size in the Asynchronous Online Discussions on the Development of Critical Thinking Skills, and on Improving Students' Performance in Online Discussion Forum
}

\author{
https://doi.org/10.3991/ijet.v14i05.9351 \\ Mohammed Kamal Afify \\ Imam Abdulrahman Bin Faisal University, Dammam, Saudi Arabia \\ mafifyeiau.edu.sa
}

\begin{abstract}
Asynchronous Online Discussions (AOD) are considered as one of the most major tools in learning management systems which are used in universities. The exploitation of AODs forums offer students the possibility to teach and learn anytime and anywhere. They also provide students with the time needed to process learning, share ideas and points of view on e-course topics. The group size in the AODs is a substantial variable that affects the interaction and the participation of students. The purpose of our research lays in understanding the influence of the group size participating in the AODs on the development of critical thinking skills in information technology for students of the Faculty of Education, and improving students' performance in online discussion forums. In this research, 103 university students from the bachelor's degree have participated in the study. The participating students are studying the Computer Application in Education Course, and the Education Technology Course on the Blackboard e-learning Management System, during a 15-week semester. The findings of the research have revealed very significant conclusions; and the researcher has come up with various recommendations and suggestions for future studies and further research.
\end{abstract}

Keywords-Asynchronous Online Discussions, group size, critical thinking, students' performance, learning Management System

\section{Introduction}

Asynchronous Online Discussions (AODs) are counted as one of the most prominent tools in learning management systems which are used in universities. The use of online discussion forums provide students with the possibility to teach and learn anytime and anywhere. They also give students the time needed to process learning, share ideas and points of view on e-course topics, as well as standing up to shyness during online discussions. Discussion forums are excellent means for students' interaction through the internet. In that, these forums constitute an important resource for promoting dialogue among students, contributing to the development of learning com- 
munities, as well as enhancing students' critical thinking, which allows greater opportunities for all students to debate and exchange opinions, and to have more time for information processing and reflection, besides peer responses with utmost quality [1], [2].

Nowadays, the usefulness of online discussion forums is no longer a matter of controversy. Many studies have questioned their efficiency; and it was proven that they are very effective in all domains. For example, In 2013 Leflay \& Groves showed beyond doubt that the use of Asynchronous Online Discussions has fostered deep learning including information processing, facts transmission, and the interpretation of the academic content [3]. In 2014, Ho has also emphasized the fact that online discussion forums affect positively the learners' motivation, their independence, and their satisfaction with the learning environment [4]. Another study conducted by Zheng, \& Warschauer revealed that the well-designed online discussions have led to increasing students' engagement and the interaction between them, which contributed to the development of their reading, writing and their language skills as a whole, as well as the results group projects and their test scores [5]. The study of Delahunty also concluded that effective learning and the learning of communication skills in higher education were achieved through the use of effective discussion in Asynchronous Discussion Forums [6].

However, the success of AODs is to some extent linked to certain variables. It has been noted from the analysis of previous studies that the quality of asynchronous discussions in online discussion forums is extremely related to both the instructional design and the characteristics and roles of the learners. The variables of the discussion forum design, the type of topics held in discussions based on higher levels of thinking, the size of the discussion group, the intrinsic motivation to engage in asynchronous discussions were considered crucial to students' interaction and their performance during the discussion; where students tend to show more involvement in asynchronous discussions when stimulated[7].Both of setting clear objectives behind the participation, and using a content-related tool are important factors for students to attract peer responses to their assignments and to increase their thinking about individual participation [8]. In parallel, the collective effectiveness, social competence, reading behavior, the dimension of time [9] and the use of peer-to-peer facilitation methods in asynchronous discussions in online forums have been proven to be helping factors in increasing students' participation and the quality of content [10]. The cognitive strategies (such as discussion, role-playing), are all considered as design variables and facilitating methods which are key factors to the success of students' interaction in asynchronous online discussions.

In the scope of searching possibilities to improve the quality of students' participation in online discussion forums, some researchers have investigated the impact of the group size on students' discussion and on some learning outcomes. However, the findings of the studies were discordant [11]. In this study, we stated that the size of the group participating in the discussion is an essential factor that requires more investigation, specifically at the level of interaction, improving participation, and the critical thinking development for students. In that, the group size in the discussion assumedly affects the learning performance. 
On the other side, critical thinking and the thinking skills have recently become, especially in the last few decades of the last century, very prominent in education due to people's awareness of the changes which took place by technology in relation to knowledge and information. The critical thinking and the digital skills are indispensable skills in 21 century. These skills help people to overcome the challenges, to solve problems, and to synthesize information, besides achieving "digital citizenship" [12], [13]. In parallel, Murphy et al have considered enabling the learners with critical thinking mechanisms is very important for knowledge construction. And they stated that developing learning environments that boost these skills is of utmost importance, besides emphasizing the importance of approaches and instructional strategies that foster critical thinking among learners during their learning process [14]. AODs are an important tool for the development of critical thinking among learners. Discussion forums have been widely adopted as an online learning tool through the internet with the potential of enhancing students' critical thinking skills, problem-solving skills, decision-making skills, and written communication skills, besides its contribution to students' ability to organize and analyze information [13], [15].

In the light of the literature reviewed and the previous studies, and the discrepancy of their results about determining the appropriate size of the discussion group, the persistent need emerges to determine the most appropriate size of the group for the discussion that can be the most influential in improving learning, developing critical thinking skills, and improving students' performance in online discussion forums within the learning management systems. As we believe, knowing the most suitable group size would enable us to recommend designers and developers of electronic environments, as well as teachers to use them in these environments.

\section{Theoretical Framework}

The theoretical framework of this research includes a review of the previous literature and the research related to this study including the theoretical foundations of electronic discussion, the importance of students' participation, the size of the discussion group, and the critical thinking in the online e-discussion environment. All of this arranged in the following sections as follows:

\subsection{Participation}

Online asynchronous discussions play a major role in promoting the interaction, which positively affects students' learning. And the technology has made the widest possible participation of students through network services; and forum participation has improved the quality of discussions. In that, participation, which was measured through interaction, has been positively correlated with academic achievement, as well as with improving students' orientation depending on the way they interact [16].

Many studies have been conducted to show the positive influence of students' participation on their own expertise in e-learning. And, it was stated that students acquire and construct in-depth knowledge through their participation in discussions, debates, 
interviews, inquiries and clarifications. Consequently, this leads to effective learning and to more participation and interaction besides creating and maintaining learning communities [16]. Nevertheless, many studies have signaled out that though interactions are of great importance, focus must be laid on the quality of these interactions and not only on their quantity [17].

The trend of students' participation in e-discussions through discussion forums has gained support of many theories. For example, the social constructivist theory sees learning as an active process which takes place often in a social context. The main assumption of the social constructivists is that learning does not happen through knowledge transmission but rather through constructing knowledge when learners participate with their peers interactively in a social context. And this process complies with the concept of interactive discussions for constructing and attaining knowledge, where the implementation of the online asynchronous discussion process is based on the idea that social dialogue is important to knowledge-construction [18]. Besides this, the use of e-discussions in learning is also recommended by the connectivism theory. The theory adopts the idea of networks and communities consisting of individuals who wish to share ideas on a common theme of learning, and in the communication model; where learners share in creating the knowledge through contributions in social networks and other forms of online communication [19]. In this research, we have used some of the principles of these theories for formulating the principles of designing an electronic discussion forum.

\subsection{Group size}

The size of the group in the online discussion group is related to the interplay and the participation of its members; and it has been positively correlated with the number of tasks presented. The group size is an important variable that affects the productivity of the group. Thereby, the size of the group deserves further investigation with respect to interaction and participation. Despite that, there are conflicting opinions and literature concerning the appropriate size of the group participating in the discussion forums; some see that small-sized groups ranging from 2 to 10 members achieve aspects of knowledge and accomplish more tasks [20]. In other literature, groups with members' number of 8 to 10 students are more suitable to maximize group interaction; and that medium-sized discussion forums are more attractive for students. they have also stated that more teacher's involvement does not reduce students' participation at any level; but there is more need to have the teacher's participation in small groups to enhance the debate [11]. In that small groups are more suitable to make contacts between students and to promote a sense of community. In addition, being in smaller groups influences positively students" communication experiences in terms of their perception of the message appropriateness and its accuracy, as well as their readiness to engage and interact with others [21].

On the other hand, previous literature has stated that discussions in large online classes or large groups lead to "increased information overload", and to a decrease in the interaction of students and teachers in the discussions [11]. In parallel, some argue that big-sized classes reduce the quality of teachers' feedback, resulting in a total 
reduction in the quality of the e-courses [22]. For more elaboration, large classes are more likely to generate more messages. Moreover, some students see such large-sized forums as congested with a huge amount of messages and content to read; so, they decide not to return to debate in the next discussions [16].

In a like manner, the results of previous research and studies have come to discord on the most appropriate size of the discussion groups. Bristol examined the effect of differences in the size of the discussion groups on enhancing learning and on improving students in a nursing program. Bristol has studied two types of groups, large: 23 participants, versus medium: 12 participants; and the strategies followed were Virtual Clinical Excursions - versus Online Discussion. The results have revealed no statistically significant differences in student results favoring a given group size or a strategy used. However, data analysis suggested that the size of the smaller group would help students "deepen" more into the content being explored [23]. In another study, AbuSeileek found that being in small groups, especially groups of (3-5) students, had a positive effect on speaking and listening skills for language learners compared to groups of (6-7) learners. Small groups have higher achievements in terms of communication skills, and in terms of having more participations among their members [24].

Kim, in turn, examined the impact of group size on students' participation in online discussion forums. The results have shown that classroom guidance and active encouragement by the teacher in small discussion groups contributed to the increased number of messages and to total students' participation in all discussion forums. On the other hand, the participations in large-sized discussion forums were limited and had a lower score of interaction among the students. The study concluded that highquality participation in large groups on the internet could be realized through splitting large group into smaller subgroups, to promote interaction during discussions [16].

In an experimental study, Shaw investigated the relationships between the group size and the participation variables on students' academic performance when learning programming language in the context of collaborative learning through electronic discussion forums. The researcher has concluded the following: the online discussion forum is useful for learning performance regardless of the group size. Moreover, that the size of the group does not have a significant impact on learning outcomes directly. On the contrary to what is proposed in social learning theory, where group discussion leads to better performance, small-sized groups affects positively the participation in learning, which affects positively learning outcomes as well, and leads to higher level of self satisfaction with learning compared to the large group [25]. Equally, the results of the study of Qiu et al. in 2014 revealed that in spite of the fact that students wrote more discussion entries when they were put in the entire classroom discussion (15-22 students), as small subgroups were created from the large group, the smaller group discussions were of more productivity in terms on quantity, and they were of more quality in terms of messages' length and the reading level. The students also showed a positive attitude towards small subgroups, where they wrote more, they were more connected with each other, and they pointed that they were more encouraged to speak, which particularly affected students language learning skills [26].

Sorensen in 2015 studied the size of the classroom on the internet and its potential impact on teacher's performance, in terms of providing good quality feedback for 
students to use continuously and effectively. The results showed that the teacher's experience may not be used effectively or consistently due to the increase in the size of the online class; and that the quality of comments and feedback of the teacher may decrease, where the overall performance of the teacher may be running short [22]. Akcaoglu and Lee as well have investigated the effect of group size on students' perception of social presence through two courses in the postgraduate level, where small group discussions were compared to the entire class discussion. The results indicated that when group discussions were held in small groups, the students achieve higher level of social presence in terms of social cohesion, social distance, and social harmony [21]. Parks-Stamm et al. in their study as well studied the effects of teacher's participation and class size on students' participation in the online discussion forum. To examine the factors contributing to the students' participation, the study analyzed the participation of the students and the teachers in asynchronous discussion forums for 500 e-courses. The results showed that there were significant differences in students' participation based on how much the teachers are participating. In small classes (less than 15 students), teacher's participation increases students' participation in the discussion forum. Whereas in intermediate classes (15-30), the teacher's participation has no effect on students participation [11].

These inconsistencies in the results of previous research and studies about the appropriate size of the online asynchronous discussion group form important stimulation for our research to determine the most appropriate size of the groups in online discussions and its impact on critical thinking development, and on students' participation in discussion forums via e-learning management system.

\subsection{Critical thinking}

Watson and Gleser defined critical thinking as complex thinking that includes skills, attitudes, and knowledge, which in turn includes an individual's ability to distinguish problems and accept generalizations in the case of logical and supporting evidence and proofs. This critical thinking also includes knowledge of logical and deductive approaches, abstraction and generalization in order to determine the value of such evidence and proofs, the degree of their validity, as well as the efficiency in applying those trends and knowledge [27]. For Gokhale, critical thinking involves asking the right questions, gathering and sorting relevant information, linking new information with the existing knowledge, reconsidering visions and opinions, reasoning, and drawing the right conclusions [28].

And to guide and supervise students' learning, the teacher's concern then is centered on providing students with cognitive strategies that enable them to think critically, make decisions, and solve problems. The results of a number of studies have revealed that online discussions can develop and enhance critical thinking skills and deep learning; because online discussion provide a natural framework for teaching critical thinking with regard to the possibility of embodying the best of traditional writing tasks as well as discussions within the classroom. Besides this, students experience more complex decision-making processes than face-to-face students do; and they also show increased participation and collaborative thinking, learn how to ex- 
press the evolving knowledge structures and negotiate it, as well as engaging in arranging and processing information by constructing personal meaning via collaborative interaction. In fact, asynchronous discussions seem to be an ideal forum for an academic discourse that promotes greater student participation, critical analysis and critical thinking, and the social construction of knowledge, while quite many others see the contrary [15], [28], [29].

The topics of discussion that enriches higher thinking skills is much vital for engaging in non-integral discussions. It was noted that the size of the moderate group of students that help to feel comfortable with the discussion is also a crucial factor in the effective learning forum. Concerning the relationship between critical thinking and the size of the discussion group, previous research results have revealed conflicting conclusions about this relationship. Wickersham and Dooley studied students' critical thinking skills during their entire class discussions. The researchers stated that when discussions are in the form of a full class, they often get off-topic; and some students dominate the conversation, and the critical thinking patterns appear as either broken or very weak. Based on these findings, the authors have recommended that by designing smaller virtual learning communities, students and teachers in online courses become more able to participate in discussions. Besides, participation will be characterized by higher degree of quality and interaction; and students remain focused on the discussion topics that develop within the forums while they manage it in a better way [30]. In another study, Hamann, et al. have compared the effects of being in a large group versus a small group on students' perceptions of the discussions' merits. Their analysis showed that when students are in smaller groups, they find discussions as more appropriate for learning and thinking critically [31]. Thereby, the purpose of our research is understanding whether critical thinking skills and students' performance in asynchronous online discussion forums are influenced by the size of the group involved in the discussion.

\section{Problem and Questions of the Research}

Providing an online discussion forum alone for students is not enough to improve learning outcomes. Rather, the process necessitates looking at the factors that help in attaining the discussion's efficiency and its quality. Through the above review of the previous research literature, there has been a discrepancy in opinion and the results of research on the appropriate size of the electronic discussion groups. The results of research, studies and opinion did not set agreement on the specific size of the electronic discussion group. Considering all of this, persistent need to determine the appropriate size of these groups rises as a vital aspect recommended by educational designers, teachers and e-facilitators as a specific criterion for designing the size of these groups. On the other hand, there are indications of a positive relationship between asynchronous online discussions and both of the thinking processes of the learner especially the critical thinking, and the performance of learners in the discussion. However, there is much paucity of research about the relationship between the 
size of the group involved in the discussion and the skills of critical thinking in online learning.

The importance of our research lies in understanding the impact of the group size participating in the asynchronous online discussion on the development of critical thinking skills among university students in an asynchronous online learning environment. More specifically, the purpose of our research is to know whether critical thinking skills and students' performance in asynchronous online discussion forums are influenced by the size of the group involved in the discussion.

The problem of our research has been identified as: "The presence of a persistent need to determine the most appropriate size for the online discussion group (large vs. medium vs. small) with regard to its impact on both the development of critical thinking skills and students' participation in discussion forums through the Blackboard elearning management system". And the following questions have been formulated:

- Q1: What is the influence of the size of the group involved in asynchronous online discussions (large vs. medium vs. small) on developing the critical thinking skills in information technology among the students of the Faculty of Education?

- Q2: What is the influence of the size of the group involved in asynchronous online discussions (large vs. medium vs. small) on improving students' performance in the e-discussion forum?

\section{$4 \quad$ Methodology}

\subsection{The methodology of the research and its variables.}

In this research, we have used descriptive research methods (descriptive survey and systems development) during the stage of studying, analyzing and designing the experimental treatment. And we have used the experimental method to measure the impact of the independent variable which is the size of the group participating in the online discussions including three sizes: large size ( $>20$ students), average size (10-20 students), and small size ( $<10$ students) on the dependent variables which are developing critical thinking skills in information technology for students of the Faculty of Education, and improving students' performance in online discussion forums.

The research used Experimental Group Pre-Test- Post-Test Design three groups in three different experimental treatments, as follows Table 1.

Table 1. Search Experimental Design

\begin{tabular}{|c|c|c|}
\hline Group & $\begin{array}{c}\text { Treatment (GS) } \\
\text { Asynchronous Online Discussions With... }\end{array}$ & Post_Test Measurement tools \\
\hline Experimental Group 1 & Large group size $(>20)$ & \multirow{3}{*}{$\begin{array}{l}\text { Critical Thinking Skills Test } \\
\text { Performance measure in Asyn- } \\
\text { chronous Online Discussions }\end{array}$} \\
\hline Experimental Group 2 & Medium group size (10-20 Student) & \\
\hline Experimental Group 3 & Small group size ( $<10$ Student $)$ & \\
\hline
\end{tabular}




\subsection{Research sample}

In this research, 103 university students from the bachelor's degree have been selected. They are studying the Computer Application in Education Couse (301N), and the Education Technology Couse (195Tech) on the Blackboard e-learning Management System. The selected students are from the Faculty of Education, Imam Abdul Rahman bin Faisal University, Kingdom of Saudi Arabia, during a 15-week semester out of a total of 125 university students in the academic year to participate in the study $(\mathrm{M}=20.34$ year, $\mathrm{SD}=0.53)$. The participants were divided into 11 groups, as shown in Table 2.

Table 2. Total No. of Sample

\begin{tabular}{|l|c|c|c|c|}
\hline \multicolumn{1}{|c|}{ Group Size } & No. Groups & Student/ Group & Total No. Students & Total Sample \\
\cline { 1 - 4 } Large $(>20)$ & 1 & 32 & 32 & \multirow{2}{*}{103 Students } \\
\cline { 1 - 4 } Medium $(10-20)$ & 3 & 12 & 36 & \\
\hline Small $(<10)$ & 7 & 5 & 35 & \\
\hline
\end{tabular}

\subsection{Design and development of the research experimental treatment}

The researcher designed the experimental Treatment and developed it by using (ADDIE) model. The ADDIE model is a systematic instructional design model consisting of five phases:

- Analysis

- Design

- Development

- Implementation

- Evaluation [32].

Analysis phase: The following steps were taken:

Analysis of the problem and needs assessment: This research is based on determining the most appropriate size of the participating group in the online discussions (large vs. medium vs. small), with regard to its influence on developing students' critical thinking skills and on improving their performance in electronic participation.

Analysis of the educational tasks and determination of general objectives: Our current research is based on some of the educational tasks which are identified in the course of Computer Applications in Education $(301 \mathrm{~N})$ and Educational Technology (195Tech). The experimental treatment was based on the study of some topics associated to the theoretical foundations and the to the basic concepts in the field of the Educational Technology. These topics rely mainly on the student's ability to practice some critical thinking skills. And this manifests clearly in some of the topics and issues covered through the course as follows: Technological awareness of the benefits of using social networks in teaching and learning as well as the risks of their usage, utilization of modern educational technology to increase awareness towards the benefits of e-reading among school students, the sources of digital learning and its impact on improving learning, besides facilitating it among learners; fields of computer usage 
in education, types of educational computer software, teaching and e-learning technology and their impact on the education system development, integrating information and communications technology into the school curriculum, strategies and methods of training teachers to adopt and publicize technological innovations in schools and educational institutions.

The abovementioned topics have been adopted as issues for discussion in asynchronous online discussion forums on the e-learning management system of the course. The general objectives of these issues and topics for discussion in the edecision have been set as follows: Acquires basic concepts associated with technological inventions in education and its applications, assessing the technological inventions available in terms of the extent to which they can be employed to achieve their educational goals, participating in the dissemination and the adoption of technological innovations in schools and in educational institutions, acquaintance with the strategies and methods of training teachers for the adoption and dissemination of technological innovations in schools, evaluating the strategies for integrating information and communication technology into the school curriculum, analyzing the uses and risks of social networks in education, evaluating the integration of information and communication technology projects in the school curriculum, evaluating the e-learning system at all aspects in the work environment (inputs, processes, outcomes), knowing the basics and the standards of designing and producing digital learning resources in the light of different learning theories to improve learning and facilitate it for the learners, determining the fields of computer use in education.

Design phase: The following steps were taken:

Design of the content organizing strategy and continuous presentation: The topics of the scientific discussions related to the content have been set in seven discussions. Each discussion lasted for two weeks. The discussions are specific course themed, linking more than one topic to the course themes, and not linked to a lesson alone in specific, to make students able of connecting subjects to each other, which may contribute to the development of critical thinking skills.

Scenario design for interaction learning strategies: The interaction environment includes all types of interaction with the teacher, the colleagues, and the content, where the basic interaction of the learner is with colleagues through the participatory discussion, and with the content as the discussions presented by the researcher stem from issues related to the subjects of the course. Besides, there is interaction with the teacher through the guidance of the teachers and their encouragement for the students. These interactions take place through the multiple possibilities offered by the forum environment of the Blackboard learning management system.

Development phase: The following steps were taken:

- Eleven unannounced closed groups have been created. This type of groups permit the members of the group only to access it and see their participations and comments associated on the discussion forum. The first group represents the largesized discussion group with 32 students. The second, the third and the fourth groups were given medium size with 12 students in each. Groups from fifth to 
eleventh were allocated to the size of the small discussion group, with 5 students in each.

- A special forum has been created for each group to address the issue under discussion according to the timeline of research experience.

- The topics of the discussions were published according to their order as mentioned earlier in 'design of the content's organizing strategy'. Each topic or issue has been discussed during 12 days; and during the thirteenth and the fourteenth days, the professor of the course presented the feedback and evaluated the students' discussions.

- A training session was held for students to train them on the right rules of asynchronous online discussions, and on how to prepare inputs and good comments. In this context, Wenger noted that it is useful to make students aware of the characteristics of good posts so that students will deliberately think and meditate in a critical way during their participation in order to gain the teacher's appreciation [33]. The students were also informed of the rules according to which the discussions would be evaluated. These rules are the ones set in the description of the critical thinking levels based on the critical thinking scale.

- The issue is raised for debate on the discussion forum in the $(\mathrm{Bb})$ system every two weeks.

- Students were instructed to engage in their discussions through their own groups, to conduct discussion processes according to the experimental design of the research. The discussions are topics derived from the course, which include several parts of the course together in the same discussion. The duration of each discussion was set in 14 days starting from the setting of the discussion's topic to urge students to participate seriously. Students were informed that $50 \%$ of their quarterly work would be allocated for the course based on the evaluation of their performance in the discussions according to the regulations governing the tests at the university.

- Students were assigned to lead the discussions in cooperation with each other, where a student leads the discussion in a group based on their wishes and the roles determined among them.

- The role of the instructor in discussions was determined as follows: enhancing the students' performance through writing some encouraging comments, directing the students to adhere to the required aspects of the discussion and reminding them of the evaluation rules when any off-topic case occurred, responding to students' queries, (most of which were related to the researcher's assessment of the quality of their participations), evaluating students' discussions based on the e- discussion evaluation criteria, then placing the evaluations in the participation analytical tables to figure out the weekly participation score.

Evaluation phase: This phase reveals the effect of achieving the experiment's objectives. The data set included the frequency of participation in the weekly discussion forum. The participation in the discussion was mandatory and contributed to the weekly participation score. The discussion forum for the course was provided with questions about one of the education and information technology issues every week, 
which corresponded to the weekly learning objectives. The weekly number of scheduled discussions and students' participation were recorded by the learning management system. At the end of the experiment, all students' contributions were counted, and evaluated on the scale of asynchronous online participations' evaluation. Besides, the critical thinking skills were evaluated through the critical thinking skills test, according to the measurement tools referred to in this research.

\subsection{Measurement tools}

The research aims to develop the critical thinking skills and improve students' performance in asynchronous online discussions. Therefore, the following measurement tools have been used:

- Critical thinking skills Test

- Asynchronous Discussions Assessment Criteria for Educational Technology Course as follows:

Critical thinking skills Scale: There are many universal standards for the measurement of critical thinking, four of which are the most common and the most dependable in the field of education. The Watson-Glaser Scale for Critical Thinking Evaluation, the Cornell Critical Thinking Scale, and California Critical Thinking Skills Test. And due to the fact that most of these measurement tools do not fit the nature of the learning strategies based on asynchronous online discussion, the researcher has adopted the measurement tool which was prepared by Abdelati to measure critical thinking skills in the field of Information and Communication Technology [34]. The scale includes 25 modules measuring five basic skills: the skill of identifying the main idea of the topic, the skill of collecting information about a topic, the skill of identifying discrepancy in information, the skill of analysis, and the skill of evaluating arguments. The total score of the scale is 100 . The validity of the scale content was verified by a number of arbitrators specialized in psychology and educational technology. Besides, its reliability was verified through applying it on a sample of students. In applying the Cronbach's alpha $(\alpha)$ equation, the reliability of the scale scored (0.83), which is an indication that the scale is of an acceptable degree of reliability. And thus the obtained results when applying the scale to the research group can be trusted.

Asynchronous Discussions Assessment Criteria: The research used a 14-item discussion evaluation criterion by Vonderwell et, al. [35], [36]. Table 3 includes the asynchronous discussion assessment criteria. 
Table 3. Asynchronous discussion assessment criteria

\begin{tabular}{|l|c|}
\hline \multicolumn{1}{|c|}{ Items } & degree \\
\hline Discussion is substantive and relates to key questions. & (1 point) \\
\hline Discussion is thought provoking, insightful, reflective, challenging. & (1 point) \\
\hline Discussion provokes interest and deeper investigation of the topic. & (1 point) \\
\hline Discussion is targeted for the knowledge construction of the group and self-learning. & (2 point) \\
\hline Posts documents, examples, etc. to be shared with the class. & (1 point) \\
\hline Uses personal/professional examples demonstrating application of key issues. & (4 point) \\
\hline Refers to readings, literature review, theory, research to discuss position and insight. & (2 point) \\
\hline Analyzes others' discussions and reflects on the issues discussed. & (1 point) \\
\hline Refers to others' discussions and addresses previous discussions posted. & (2 point) \\
\hline Offers solutions and suggestions to the issues raised. & (1 point) \\
\hline Initiates discussion raising an issue, concern, suggestion. & (1 point) \\
\hline Demonstrates understanding and interest in the topic. & (1 point) \\
\hline Feedback to class members is constructive, specific, and supportive. & (5 point) \\
\hline Demonstrates timely and valuable online presence. & 25 \\
\hline Total & \\
\hline
\end{tabular}

\section{Research Results}

Answer to Q1: What is the influence of the size of the group involved in asynchronous online discussions (large vs. medium vs. small) on developing the critical thinking skills in information technology among the students of the Faculty of Education?

One-way analysis of variance (ANOVA) was calculated to show the effect of the size (large vs. medium vs. small) of the group involved in asynchronous online discussions on developing critical thinking skills in Information and Communication Technology. The obtained results are shown in Table (4) for descriptive statistics of the arithmetic averages and standard deviations of the group size, and table (5) for the analysis of the one-way analysis of variance as follows:

Table 4. Table (4): Arithmetical averages and standard deviations for groups sizes (Large, Medium, Small) in the after-performance of the Critical Thinking Skills Scale

\begin{tabular}{|c|c|c|c|c|c|c|}
\hline \multirow{2}{*}{ Group Size Test } & \multicolumn{2}{|c|}{ Large (>20) } & \multicolumn{2}{c|}{ Medium (10-20) } & \multicolumn{2}{c|}{ Small $<\mathbf{1 0}$} \\
\cline { 2 - 7 } & Mean & SD & Mean & SD & Mean & SD \\
\hline Critical Thinking Skills Test & 75.12 & 5.99 & 85.97 & 6.58 & 88.63 & 5.98 \\
\hline
\end{tabular}

Table 5. ANOVA, Analysis of the one-way variation of the group size effect (large, medium, Small) on the critical thinking skills

\begin{tabular}{|l|c|c|c|c|c|}
\hline $\begin{array}{c}\text { Variable } \\
\text { source }\end{array}$ & Sum of squares & df & Means Squares & "F" value & $\begin{array}{c}\text { Significance } \\
\text { Indicator }\end{array}$ \\
\hline Between Groups & 3385.10 & 2 & 1692.55 & \multirow{2}{*}{0.000} \\
\hline Within Groups & 3850.64 & 100 & 38.51 & \multirow{2}{*}{0.93 .95} & \\
\hline Total & 7235.74 & 102 & & & \\
\hline
\end{tabular}


The results in the above table (5) indicate statistically significant function value differences at (0.01) among the average scores of students in all critical thinking skills as a whole, and the critical thinking test as a whole, where the " $F=74.95$ " value were significant in all critical thinking skills test. This in the first place depicts the effect of group size on the development of students' critical thinking skills. To determine the position of these differences, the Scheffé's post hoc test [37] was used to detect differences between groups in binaries as shown in table (6).

Table 6. The post binary comparisons between the test score averages of the critical thinking skills for the three research groups

\begin{tabular}{|l|l|c|c|c|}
\hline \multicolumn{1}{|c|}{ Style (I) } & \multicolumn{1}{|c|}{ Style (j) } & Mean deferent (I-J) & $\begin{array}{c}\text { Significance Indi- } \\
\text { cator }\end{array}$ & $\begin{array}{c}\text { Size effect } \\
\text { (Eta Square } \boldsymbol{\eta 2} \text { ) }\end{array}$ \\
\hline \multirow{2}{*}{ Large $(>20)$} & Medium $(10-20)$ & -10.847 & 0.000 & \multirow{2}{*}{0.468} \\
\cline { 2 - 4 } & Small $<10$ & -13.504 & 0.000 & \\
\hline Medium $(10-20)$ & Small $<10$ & -2.656 & 0.202 & \\
\hline
\end{tabular}

The results in table (6) above indicate that the participating small-sized and medium sized groups achieved higher results in critical thinking skills than the performance of the large groups. There were statistically significant function value differences at (0.01) between the small besides medium groups and the large-sized group in their performance in critical thinking skills test. The difference was in favor of students' performance in small-sized and medium-sized groups. Whereas there was no statistically significant difference between the performance of the medium-sized groups compared to the small-sized groups in their performance in the critical thinking skills test.

Besides, the size effect was calculated using the Eta Square Equation $\eta 2$ [38]. The magnitude's value of the impact between the participating groups, the small, mediumsized and the large-sized group reached $(0.468)$ in the critical thinking test. This finding indicates that there is a significant impact of the independent variable in the difference between the two groups in terms of the development of critical thinking skills. These differences affirm that the treatment showed strong impact on the students' performance in the medium-sized groups compared to the students' performance in the large-sized group in the critical thinking test.

Answer to Q2: What is the influence of the size of the group involved in asynchronous online discussions (large vs. medium vs. small) on improving students' performance in the e-discussion forum?

The One-way analysis of variance (ANOVA) was calculated for the participating groups in online discussions to show the groups' size effect (large vs. medium vs. small) on improving students' performance in the e- discussion forum. The results were as shown below: Table (7) for descriptive statistics of arithmetical averages, and standard deviations of the group size, and table (8) for one-way analysis of variance (ANOVA). And the results are as follows: 
Paper-The Influence of Group Size in the Asynchronous Online Discussions ....

Table 7. Arithmetic averages and standard deviations of the groups size (Large, Medium, Small) in the after-performance evaluation of Asynchronous Online Discussion

\begin{tabular}{|c|c|c|c|c|c|c|}
\hline \multirow{2}{*}{ Group Size Test } & \multicolumn{2}{|c|}{ Large (>20) } & \multicolumn{2}{c|}{ Medium (10-20) } & \multicolumn{2}{c|}{ Small $<\mathbf{1 0}$} \\
\cline { 2 - 7 } & Mean & SD & Mean & SD & Mean & SD \\
\hline Asynchronous Discussion Assessment Criteria Test & 14.59 & 2.16 & 21.31 & 2.41 & 21.71 & 2.53 \\
\hline
\end{tabular}

Table 8. ANOVA, One-way variation analysis of the groups' size effect (Large, Medium, Small groups) On the after-performance for the evaluation scale of Asynchronous Online Discussions

\begin{tabular}{|l|c|c|c|c|c|}
\hline $\begin{array}{c}\text { Variable } \\
\text { source }\end{array}$ & Sum of squares & df & Means Squares & "F" value & $\begin{array}{c}\text { Significance } \\
\text { Indicator }\end{array}$ \\
\hline Between Groups & 1057.21 & 2 & 528.60 & \multirow{2}{*}{0.310} & \multirow{2}{*}{0.000} \\
\hline Within Groups & 566.50 & 100 & 5.66 & & \\
\hline Total & 1623.71 & 102 & & \\
\hline
\end{tabular}

The results in Table 8 show that there are statistically significant function value differences at (0.01) among the average scores of students in their performance on the asynchronous online discussions' evaluation scale, where the " $F$ " values were significant, which means that the size of the group has an impact on the students' performance in the Asynchronous Online Discussion forums. To specify the location of these differences, the Scheffé's post hoc test was used to detect the differences between the groups in the binaries, as shown in Tab (9).

Table 9. The post binary comparisons between the test score averages of the the evaluation scale of Asynchronous Online Discussions for the three research groups

\begin{tabular}{|l|l|c|c|c|}
\hline \multicolumn{1}{|c|}{ Style (I) } & \multicolumn{1}{|c|}{ Style (j) } & $\begin{array}{c}\text { Mean defer- } \\
\text { ent (I-J) }\end{array}$ & $\begin{array}{c}\text { Significance } \\
\text { Indicator }\end{array}$ & $\begin{array}{c}\text { Size effect } \\
\text { (Eta Square } \boldsymbol{\eta} \text { 2) }\end{array}$ \\
\hline \multirow{2}{*}{ Large $(>20)$} & $\begin{array}{l}\text { Medium (10- } \\
\text { 20) }\end{array}$ & -6.71 & 0.000 & \multirow{2}{*}{0.651} \\
\cline { 2 - 4 } & Small $<10$ & -7.12 & 0.000 & \\
\hline Medium $(10-20)$ & Small $<10$ & -0.409 & 0.770 & \\
\hline
\end{tabular}

The results in table (9) above indicate that the participating small-sized and medium sized groups achieved higher results in the performance of the students and their effectiveness in the online discussion forums than the performance of the large groups. There were statistically significant function value differences between the small besides medium groups as opposed to the large-sized group in their performance in the asynchronous online discussion test scale. The difference was in favor of the students' performance in small-sized and medium-sized groups. Whereas there was no statistically significant difference between the performance of the mediumsized groups compared to the small-sized groups in their performance in asynchronous online discussion test.

Besides, the impact's degree was calculated using the Eta Square Equation $\eta 2$. The magnitude's value of the impact between the participating groups, the small, mediumsized and the large-sized group reached $(0.651)$. This result indicates that there is a significant impact of the independent variable in the difference between the two groups in terms of improving students' performance in asynchronous online discus- 
sion forums. These differences affirm that the treatment has strong impact on the students' performance in the small and medium-sized groups compared to the students' performance in large-sized groups.

\section{Discussion and Explanation of the Results}

The results of the research have shown that students who have studied in smallsized discussion groups $(\mathrm{GS}=5)$ and medium-sized discussion groups $(\mathrm{GS}=12)$ were more positive in all critical thinking skills, and also in performance improvement in online discussion forums than students who have studied in the large-sized discussion group $(\mathrm{GS}=32)$. The findings have also shown that there are no differences between small and medium-sized groups in their impact on critical thinking skills, and performance improvement in online discussion forums among the research sample. The researcher attributes these results to the following reasons:

The researcher sees that one of the main reasons for the small and medium-sized discussion groups preponderance over large-sized discussion group in all critical thinking skills, as well as in students' performance improvement in online discussion forums, is that both small-sized and medium sized groups provided a bigger opportunity for concentration and effective participation in online discussion forums. In that small and medium number of students ensures better opportunity to have deep knowledge through dialogue, asking questions, collecting information from various sources on the issue under discussion, investigation and also reading all of their colleagues' comments to study them more attentively. Thus, there was greater opportunity to analyze, evaluate, build and integrate them and eventually make decisions as well as suggesting effective solutions for issues under discussion which fits for critical thinking skills. This view is supported by Shaw [25] and Kim [16] through stating the fact that active participation leads to active learning and helps to create active learning communities, which is considered as an important factor in achieving highquality learning outcomes, especially in terms of thinking skills, including critical thinking skills. By doing so, students build and acquire in-depth knowledge through participating in discussions, debates, questioning, inquiries, clarifications, resource collection then analyzing and reviewing them, leading to effective learning, greater participation and interaction, as well as the development of critical thinking skills.

These results come in consistency with the results of many previous studies. Bristol found out that the small-sized groups can help students "deepen more" into the content being explored [23]. AbuSeileek found that being part of small groups of (35 ) students influenced positively the speaking and listening skills for language learners compared to groups of (6-7) learners [24]. In that small groups had higher achievements in terms of communication skills, and more participations among their members. Qiu et al. [26] discovered that when small subgroups were created out of a large group, small group discussions were quantitatively more productive and qualitatively higher in terms of message length and reading level. Stating the obvious, the students' presence in smaller groups influences positively their communication expe- 
riences in terms of their awareness towards the appropriateness and the accuracy of messages, as well as their willingness to engage and interact with others [21].

On the opposite, the researcher believes that the participation of a large number of students in the discussion has led to students' dispersion between the different views, and reduced their ability to follow up all comments and participations and to see all the educational materials available. So much of their opinion was superficial and not deepened sufficiently to strengthen their critical skills. In parallel, as indicated by the results of a number of previous studies, the researchers have found that when students are in larger groups, they become less engaged in higher thinking skills; so they produce fewer dialogues; ask fewer questions, with less engagement in discussions. Besides, some members may dominate the discussion inappropriately [31], [16]; while others claimed that larger-sized classrooms reduces the quality of teachers' feedback, resulting in a total reduction in the quality of the e-course [22].

On the other hand, analysis of students' participation in e-discussion forums showed that online discussion stimulates thinking at higher levels for students. This is because online discussion provides a natural framework for teaching critical thinking skills because it allows students to practice critical thinking skills. During the discussion of the course issues, the students were required to identify the main idea of the topic; then asked to collect information about the topic of the discussion, and then again instructed to identify the discrepancy in the information, analyze the information and formulate hypotheses, evaluate proofs and at last finding solutions for the issue under discussion. functionally, all of this contributed to development of critical thinking skills, which in the end complies with the previous studies that see the online discussion as a factor that enhances critical thinking skills [15], [28], [29].

This result is also supported by the cognitive load theory, which suggests that the multiplicity of learning resources increases the loading burden on the memory, and does not help in clarifying the learning material. But rather, it reduces the capacity of the learner's active memory, which results in cognitive plus load that may lead to debilitating the entire learning process. Previous literature has also suggested that discussions in large online classes or groups can cause "increased information overload", and a decrease in students and teachers' interaction in the discussion [11]. Thereby, through applying the principles of this theory on this research, we find that it gives preference to the participation of fewer learners in online discussions so as to avoid additional cognitive burden on them and instead allow them to follow the views of colleagues and respond to them. On the other hand, the social interdependence theory confirms that when the group is larger, the members' need to be skilled in coordinating their efforts increases. Therefore, group discussions in online forums derived from social interdependence are influenced by the size of the collaborating group [39].

\section{Conclusion}

The results of the experimental study in this current research found that the size of the group participating in the online discussions has an influence on developing criti- 
cal thinking skills and on improving the performance in the online discussion forums within the learning management systems for the university students. The findings revealed that the students who have studied in the small-sized discussion groups (5 students) and medium-sized groups (12 students) were more positive in all critical thinking skills and in performance improvement in online discussion forums, compared to the students who studied in large-sized discussion group (32 students). Also, It was found that there were no differences between small and medium-sized groups in their influence on critical thinking skills and performance improvement in online discussion forums among the sample students.

Among the implications of the practice is that small and medium-sized discussion forums are more attractive for students; also, there is a certain need for teachers' participation in small groups to enhance the discussion. Accordingly, this result should be taken into consideration when designing traditional and online learning environments, especially if the results of future studies and research support these findings.

The results of this research are important because they reflect the relationships between the group size participating in online discussion forums and the development of critical thinking skills as well as the performance improvement in online discussion. Given the importance of discussions in online learning contexts, we hope that the results of our research will be useful for teachers, educational designers and for other researchers who have participated equally through efforts aiming at enriching our collective understanding of students' knowledge construction in online discussions.

In the same context, this current research suggests further research on other variables of online discussion environment design, such as research strategies for determining the learners' roles in online discussions, the influence of role rotation among students on some learning outcomes, and the impact of teacher's participation (participating/ not participating) in the discussion and the interaction with groups sizes (small, medium, large) to combine efforts enriching the researchers' understanding of constructing students' knowledge in asynchronous online discussions through elearning management platforms.

\section{$7 \quad$ References}

[1] Tan, K. E. (2017). Using online discussion forums to support learning of paraphrasing. British Journal of Educational Technology, 48(6), 1239-1249. https://doi.org/1 $0.1111 /$ bjet.12491

[2] de Fátima Goulão, M. (2014). Performance of students in an online asynchronous work. Procedia-Social and Behavioral Sciences, 116, 4673-4677. https://doi.org/10.101 6/j.sbspro.2014.01.1006

[3] Leflay, K., \& Groves, M. (2013). Using online forums for encouraging higher order thinking and 'deep'learning in an undergraduate Sports Sociology module. Journal of Hospitality, Leisure, Sport \& Tourism Education, 13, 226-232. https://doi.org/10. 1016/j.jhlste.2012.06.001

[4] Ho, K. K. (2014). The Role of Learners' Academic Background On E-Learning: An Empirical Study on The Use of Discussion Forum. International Journal of Systems and Service-Oriented Engineering (IJSSOE), 4(4), 51-64.

https://doi.org/10.4018/ijssoe.2014100104 
[5] Zheng, B., \& Warschauer, M. (2015). Participation, interaction, and academic achievement in an online discussion environment. Computers \& Education, 84, 78-89. https://doi.org/10.1016/j.compedu.2015.01.008

[6] Delahunty, J. (2018). Connecting to learn, learning to connect Thinking together in asynchronous forum discussion. Linguistics and Education, 46, 12-22. https://doi.org/10.1 016/j.linged.2018.05.003

[7] Hall, M. T., \& Marshall, J. E. (2016). Intrinsic and Extrinsic Motivation within the Context of Modern Education. In Handbook of Research on Applied Learning Theory and Design in Modern Education (pp. 292-308). IGI Global https://doi.org/10.4018/978-1-4666-9634$1 . \operatorname{ch} 014$

[8] Chen, B., Chang, Y. H., Ouyang, F., \& Zhou, W. (2018). Fostering student engagement in online discussion through social learning analytics. The Internet and Higher Education. https://doi.org/10.1016/j.iheduc.2017.12.002

[9] Goggins, S., \& Xing, W. (2016). Building models explaining student participation behavior in asynchronous online discussion. Computers \& Education, 94, 241-251. https://doi.org/10.1016/j.compedu.2015.11.002

[10] Szabo, Z. (2015). BETTER TOGETHER: TEAMS AND DISCOURSE IN ASYNCHRONOUS ONLINE DISCUSSION FORUMS. Journal of Psychological \& Educational Research, 23(1).

[11] Parks-Stamm, E. J., Zafonte, M., \& Palenque, S. M. (2017). The effects of instructor participation and class size on student participation in an online class discussion forum. British Journal of Educational Technology, 48(6), 1250-1259. https://doi.org/10.1111/bjet.12512

[12] Higgins, S. (2014). Critical thinking for 21 st-century education: A cyber-tooth curriculum? Prospects, 44(4), 559-574. https://doi.org/10.1007/s11125-014-9323-0

[13] Gao, J., Guo, W., \& Wang, M. (2017, December). Learners' Critical Thinking Characteristics in Asynchronous Online Discussion. In Educational Innovation through Technology (EITT), 2017 International Conference of (pp. 70-74). IEEE.

[14] Murphy, P. K., Rowe, M. L., Ramani, G., \& Silverman, R. (2014). Promoting criticalanalytic thinking in children and adolescents at home and in school. Educational Psychology Review, 26(4), 561-578. https://doi.org/10.1007/s10648-014-9281-3

[15] Klisc, C., McGill, T., \& Hobbs, V. (2017). Use of a post-asynchronous online discussion assessment to enhance student critical thinking. Australasian Journal of Educational Technology, 33(5), 63-76.

[16] Kim, J. (2013). Influence of group size on students' participation in online discussion forums. Computers \& Education, 62, 123-129. https://doi.org/10.1016/j.compedu.2012.10.025

[17] Milman, N. B. (2017). Designing Asynchronous Online Discussions for Quality Interaction in Asynchronous Online Courses. Distance Learning, 14(3), 61-63.

[18] De Wever, B., Van Keer, H., Schellens, T., \& Valcke, M. (2010). Roles as a structuring tool in online discussion groups: The differential impact of different roles on social knowledge construction. Computers in Human Behavior, 26(4), 516-523. https://doi.org/10.1016/j.chb.2009.08.008

[19] Siemens, G. (2005). Connectivism: A learning theory for the digital age. International Journal of Instructional Technology and Distance Learning (ITDL), 2(1). pp. 3-10.

[20] Hew, K. F., \& Cheung, W. S. (2011). Higher-level knowledge construction in asynchronous online discussions: An analysis of group size, duration of online discussion, and student facilitation techniques. Instructional Science, 39(3), 303-319. https://doi.org/10.10 $\underline{07 / \mathrm{s} 11251-010-9129-2}$ 
[21] Akcaoglu, M., \& Lee, E. (2016). Increasing social presence in online learning through small group discussions. The International Review of Research in Open and Distributed Learning, 17(3). https://doi.org/10.19173/irrodl.v17i3.2293

[22] Sorensen, C. (2015). An Examination of the Relationship between Online Class Size and Instructor Performance. Journal of Educators Online, 12(1), 140-159. https://doi.org/1 0.9743/JEO.2015.1.3

[23] Bristol, T. J., \& Kyarsgaard, V. (2012). ASYNCHRONOUS DISCUSSION: A Comparison of Larger and Smaller Discussion Group Size. Nursing education perspectives, 33(6), 386-390. https://doi.org/10.5480/1536-5026-33.6.386

[24] AbuSeileek, A. F. (2012). The effect of computer-assisted cooperative learning methods and group size on the EFL learners' achievement in communication skills. Computers \& Education, 58(1), 231-239. https://doi.org/10.1016/j.compedu.2011.07.011

[25] Shaw, R. S. (2013). The relationships among group size, participation, and performance of programming language learning supported with online forums. Computers \& Education, 62, 196-207. https://doi.org/10.1016/j.compedu.2012.11.001

[26] Qiu, M., Hewitt, J., \& Brett, C. (2014). Influence of group configuration on online discourse writing. Computers \& Education, 71, 289-302.

[27] Watson, G \& Glaser, E. (2008). Watson - Glaser Critical Thinking Appraisal Short Form Manual. Pearson Education, Inc. https://doi.org/10.1016/j.compedu.2013.09.010

[28] Gokhale, A. (2018). Guided Online Group Discussion Enhances Student Critical Thinking Skills. International Journal on E-Learning, 17(2), 157-173.

[29] Hall, R. A. (2015). Critical Thinking in Online Discussion Boards: Transforming an Anomaly. Delta Kappa Gamma Bulletin, 81(3).

[30] Wickersham, L. E., \& Dooley, K. E. (2006). A content analysis of critical thinking skills as an indicator of quality of online discussion in virtual learning communities. Quarterly Review of Distance Education, 7(2), 185.

[31] Hamann, K., Pollock, P. H., \& Wilson, B. M. (2012). Assessing student perceptions of the benefits of discussions in small-group, large-class, and online learning contexts. College Teaching, 60(2), 65-75. https://doi.org/10.1080/87567555.2011.633407

[32] Branch, R. M. (2009). Instructional design: The ADDIE approach (Vol. 722). Springer Science \& Business Media. https://doi.org/10.1007/978-0-387-09506-6

[33] Wenger, E. (2010). Communities of practice and social learning systems: the career of a concept. In Social learning systems and communities of practice (pp. 179-198). Springer, London. https://doi.org/10.1007/978-1-84996-133-2_11

[34] Abdelati, H. A. (2008). Critical thinking in the information age. Information studies, 2, 149-180.

[35] Vonderwell, S., \& Zachariah, S. (2005). Factors that influence participation in online learning. Journal of Research on Technology in education, 38(2), 213-230. https://doi.org/10.1080/15391523.2005.10782457

[36] Vonderwell, S., Liang, X., \& Alderman, K. (2007). Asynchronous discussions and assessment in online learning. Journal of Research on Technology in Education, 39(3), 309-328. https://doi.org/10.1080/15391523.2007.10782485

[37] Holmbeck, G. N. (2002). Post-hoc probing of significant moderational and mediational effects in studies of pediatric populations. Journal of pediatric psychology, 27(1), 87-96. https://doi.org/10.1093/jpepsy/27.1.87

[38] Fan, X. (2001). Statistical significance and effect size in education research: Two sides of a coin. The Journal of Educational Research, 94(5), 275-282. https://doi.org/10.10 $\underline{80 / 00220670109598763}$ 
[39] Bertucci, A., Conte, S., Johnson, D. W., \& Johnson, R. T. (2010). The impact of size of cooperative group on achievement, social support, and self-esteem. The Journal of General Psychology: Experimental, Psychological, and Comparative Psychology, 137(3), 256-272 https://doi.org/10.1080/00221309.2010.484448

\section{Author}

Mohammed Kamal Afify is an associate professor of educational technology in college of education at Imam Abdulrahman Bin Faisal University, Saudi Arabia. He has authored numerous articles in the field and published extensively in different areas. His research interests vary from applying educational technology in higher education to quality standards and implementations in eLearning environments.

Article submitted 2018-08-06. Resubmitted 2018-10-14. Final acceptance 2018-10-14. Final version published as submitted by the authors. 